\title{
Understanding FDI Spillover Effects: Evidence from North Macedonia
}

\author{
SNEZHANA HRISTOVA \\ University American College Skopje, Nothern Macedonia \\ shristova@uacs.edu.mk \\ DUSICA STEVCEVSKA-SRBINOSKA \\ University American College Skopje, Nothern Macedonia \\ dusica@uacs.edu.mk
}

This paper examines theoretically and empirically the spillover effects of FDIs in North Macedonia: The research focuses on the implications from business-to-business (в2 в) relations between local companies and multi-national enterprises (MNES) operating in the free economic zones (TIDZ) in North Macedonia: A specially designed survey was conducted with 28 domestic companies, half of which work with the foreign companies operating in the free economic zones in North Macedonia: The statistical analysis is based on the equality tests regarding the sample mean ( $t$-test and ANova) and median (Chi-square and Kruskal-Wallis test) of the above mentioned two sub-sets of data The research findings suggest that in general FDIs encourage stable connections between local companies, suppliers and customers, but do not increase the awareness of local companies about the importance of marketing for their business development. There is also insufficient empirical support for the assumption that cooperation with FDIs has significant influence on the investment decisions of the local companies, or that FDIs stimulate the search for innovative methods of production and organizational practices. Aside from the direct economic benefits from the presence of foreign companies in a host country, such as capital accumulation, increased employment rates, higher salaries, and better working conditions, it is expected that indirect effects will also occur, desirably in form of productivity spillovers, which will further enhance economic growth and development, as well as promote business environment and competitiveness. Regarding practical implications, these findings can help policymakers and company managers to recognize the different FDI spillover effects on domestic businesses' output. Moreover, policymakers need to encourage the capability of local buyers to integrate the advanced products and services purchased from foreign firms. Furthermore, this study contributes to the existing research base in this field and represents one of the pioneer attempts in the case of RNM. The results gained from the research are very important for companies themselves, but they can also serve as a starting 
point for future research to eliminate governmental and other corporate issues related to the relationship between domestic and foreign businesses.

Key words: FDI, spillover effects, business environment and competitiveness

https://doi.org/10.26493/1854-4231.15.58-79

\section{Introduction}

One very relevant aspect for development of the business environment in the economy and promotion of the business-to-business relations, are the foreign direct investments (FDIS). FDIS are in general considered as important source of finances, especially for underdeveloped and developing countries. However, the benefits for the local companies, in terms of increased labour productivity through international transfer of knowledge and technology, are even more important. Strongly emphasizing the indirect effects of the FDIs makes local companies to be often identified as major growth-enhancing factor for the host economy. Developing countries tend to attract prospective companies with offers of tax breaks, subsidies and other incentives to set up green field investments. While these concessions may result in lower corporate tax revenues in the short-run, the economic benefits and the enhancement of local human capital can deliver positive returns over the long-run. Having in mind the afore-mentioned, the aim of this paper is to examine theoretically and empirically the spillover effects of the FDIs in the Republic of North Macedonia. More specifically, in the focus of the research are the implications from business-to-business (в2в) relations between the local companies and the multi-national enterprises (MNES) operating in the free economic zones in North Macedonia. The key research question is to detect the key driver behind FDI spillover effects. There are assumptions that compared to domestic companies, multinational enterprises often have more advanced technology, employ higher number of skilled workers, and spend more resources on research and development (R\&D). This argument is at the same time an essential requirement and precondition for multinational enterprises to expand their production in a foreign country. MNEs have to be more efficient than the local competitors (Buckley et al. 2005). On the other hand, local companies are believed to be more knowledgeable about the domestic markets, the local business environment and local factors of production (Blomström and Kokko 2001; 
Blomström and Sjöholm, 1999; Cuyvers et al. 2008). In such a situation, it is likely that different types of externalities occur, causing spillover effects from mNEs to local companies, both within the industrial sector, horizontally, and between sectors (among related companies such as suppliers), vertically.

\section{Literature Review}

The theoretical review on the implications of FDis on the host economy indicates that besides direct implications such as capital accumulation and increased level of employment, important aspect are the positive externalities (indirect implications) that foreign companies might generate in the host economy. However, FDIs should not be viewed as automatic growth-generating instrument. Hence, governments should not rush in decisions to attract FDIs as much as possible, offering various benefits for foreign investors to move the capital in their countries. It is important to have in consideration that the price paid to attract more FDI inflows might not often pay off, especially from the point of view of the expected indirect effects. The main rationale behind the growth effects of FDI and special incentives to attract FDI is the belief that they produce externalities in the form of technology transfers and spillovers (Carkovic and Levine 2002). Romer (1993) argues that FDI can ease the transfer of technological and business know-how to less developed countries and enhance the productivity of all firms in the host country. In this understanding, although foreign direct investments are not in general considered as important source of finances, especially for underdeveloped and developing countries, the benefits for the local companies become even more important. A strongly emphasized indirect effect of the FDIs makes them often identified as major growth-enhancing factor for the host economy. Overall, the positive implications and benefits of FDIS are widely recognized. Countries are more focused in creating favourable business environment for foreign investors, thus encouraging increased capital movement across the borders. Areas of positive implications of FDIs are often pointed out within the trade effects, human capital contribution, spillover effects, competition level, management practices, and the like. FDIs influence economic growth by increasing total factor productivity and the efficiency of resource use in the host country. It increases the capital stock and thus raises the output levels. Also, the contribution to human capital is significant. Multinational enterprises reduce the unemployment and usually provide higher wages and better working conditions (upward pressure on wages in the host economy), due to 
their higher productivity, which is explained by greater technological know-how and modern management skills. The transfer of technological and managerial know-how through affiliates also gives rise to direct benefits and increases competitiveness in host countries (Parnell 2014). Guided by the idea to increase the quality of their suppliers, MNES can also provide technical assistance, training and other information for their local partners, thus causing spillover effects, beneficial for the business environment in the country. The presence of MNES stimulates domestic competition, thereby leading to higher productivity, innovation, lower prices and more efficient resource allocation. FDIs through acquisition of local firms result in changes in the management and corporate governance. MNES generally impose their own company policies, internal reporting systems and principles of information disclosure, thus improving the business environment and developing the corporate efficiency. Moreover, multinationals may contribute to higher productive efficiency and better use of the existing resources by the local companies. Also, they can impact on breaking down local monopolies and fostering market competition, introduction of new know-how, increase of the managerial efforts of the local companies for adoption of new marketing techniques and search for new technologies (Kokko 1992; Saggi 2002). Navaretti, Venables, and Barry (2004) also argue that FDIs will put an upward pressure on the wages in the host economy, especially for unskilled workers. Also, as multinational enterprises often use superior production technology, through on-the-job trainings, FDIs can upgrade the skills of the local workers. Given the aforementioned, the host economy can benefit not only directly from the increased productivity, but indirectly, through higher collection of tax revenues, due to the higher wages (Bruhn and Calegario 2014). Overall, it is widely accepted that the entry of multinational enterprises (MNES) generates a net positive effect on the local firms' productivity in the host countries (Cuyvers et al. 2008).

Although there are strong theoretical basis suggesting positive externalities of the presence of foreign direct investments, empirical literature on the other hand provides mixed results, especially regarding the necessary preconditions for efficient spillover effects. Some of these vital factors are the 'absorptive capacity', democratic political systems, and minimum governance quality of the host economy (Elkomy, Ingham, and Read 2016). Others are related with the host country's capability to benefit from technological spillovers from the more industrialized nations and the ability to accumulate and best utilize technology and knowledge (Narula and Portelli 
2004). The main determinant of the 'absorptive capacity' is the quality of institutions, particularly, the rule of law and the property rights protection. However, countries do not always experience the same benefits from FDIs. Their contribution depends on the policy and business environment of the host economies. While a foreign investment may be beneficial for one country, it might even be quite harmful for another. Gorodnichenko, Svejnar, and Terrell (2007) do not find any evidence in favour of the hypothesis that technologically more advanced countries will experience greater spillover effects from FDIs. Additionally, although business environment in the host economy affects the efficiency of the local companies, the authors find no evidence that it influences the strength of the spillover effects, neither measured by the level of corruption, bureaucracy, or differences in the level of development on regional level.

Given the consensus that FDI inflows have greater importance for the economic growth and development in underdeveloped and developing countries, very often the interest is turned exactly towards those countries. Lalitchandra (2015) supports the thesis that FDI inflows are the most effective source of capital and important factor for economic growth in developing countries, with an emphasis on productivity gains. However, Gerschewski (2013) suggests that there is a tendency of negative intra-industry (horizontal) productivity spillovers in developing countries. The arguments offered in relation to this suggestion are the following. First, the entrance of multinational enterprises on the local market might lead to crowding-out of the local companies. Second, the absorptive capacity of the local companies might not be sufficient to assimilate the knowledge of MNES. Still, there is evidence of positive inter-industry (vertical) spillover effects, mostly backwards, or directed to the local suppliers and contractors from different industrial sector. Local companies in this case might experience important benefits from their cooperation with multinational enterprises operating in the country.

Focusing on the transition countries, Krammer (2010) shows that the countries from Eastern Europe experience greater productivity gains from the FDIs compared to the countries from the Western part of Europe, emphasizing thus the disparities between the two regions. While the capital stock in the Western European countries plays an important role for the total factor productivity, in the eastern countries it is less significant.

As former socialist countries, the Czech Republic and Romania have both experienced great economic development and increased stock of foreign direct investments in the recent years. Javorcik 
and Spatareanu (2005) provide comparative analysis regarding the spillover effects of the FDIs in these two countries (horizontal and vertical), but they find no evidence of their existence. On the other hand, Jude (2012), for the case of Romanian companies for the period of 1999 to 2007, finds positive backward and negative forward spillover effects. Also, he finds that technological spillovers are positively correlated with the technological gap, whereas for the horizontal spillover effects, labour mobility is the only one significant. Similarly, Stancik (2007), using firm level data for the period 19952003 for Czech companies, concludes that domestic companies are in general negatively affected by foreign ones, thus suffering from their presence. He opposes the arguments for subsidization of foreign direct investments, as booster of economic activity, given that he does not find any presence of forward vertical spillovers, whereas horizontal and backward spillovers are negative.

Nicolini and Resmini (2010) investigate the spillover effects in Romania, Poland and Bulgaria. By using unbalanced panel data for more than 40.000 domestic companies from the manufacturing sector, and around 10.000 foreign companies operating in these countries, they tend to provide answers about the existence of indirect effects, whether they occur within sectors or between them, and what factors those determine. They find that spillovers within sectors mostly arise in labour intensive sectors, whereas spillovers between sectors are typical for high-tech sectors. Additionally, they relate the extent and intensity of the spillovers with the absorptive capacity of domestic companies, while the results differ depending on the size and the technological development as well. Vahter and Masso (2004) takes into account the market orientation of FDIs in Estonia and Slovenia (local market orientation, or export orientation), in terms of productivity and spillover effects. Namely, he finds that local market oriented foreign companies in Estonia have much higher labor productivity than export oriented, whereas in Slovenia such relationship does not exist. He finds no spillover effects from the FDIs to domestic companies in Estonia. On the contrary, there are positive spillovers for local companies in Slovenia, which leads to conclusion that existence of positive spillover effects might depend on the economic development of the host country. Still, there are authors which despite of the provided theoretical and empirical evidences of the spillover effects of the FDIs have contrasting claims. Namely, there are cases where empirical research failed to provide support for the hypothesis that FDI inflows would boost the economic activity and improve the business environment of the host 
economy. For example, Marin and Bell (2006) failed to identify automatically delivered FDI spillover. Furthermore, they have taken into consideration the absorptive capacities as possible a factor that influences the extent of spillovers, but still, did not find any support for that either. Additionally, they associate spillover effects with investments of domestic companies in capital embodied technology, as well as with skill training, even though to lesser extent, while in contrast, research and development investments are found unimportant. Therefore, they question the relevance of the whole R\&D based governmental policies. In this regards, Karahan (2016) investigates the relationship between FDI inflows and economic growth in Turkey and finds no positive spillover effects of FDIs. He concludes that benefits from attracting FDIs in developing countries do not occur automatically and without additional efforts. Therefore, the suggestion is that policy makers in the host economy should focus equally on attracting FDIs and on improving local economic conditions and business environment. For the case of North Macedonia, referring to United Nations Conference on Trade and Development, Jovanovikj (2016) underlines that linkages between domestic and foreign companies in North Macedonia are in general weak, especially for export oriented Greenfield investments, which import most of the production inputs. For existing companies acquired by foreign investors, there is a reverse situation, or tendency to upgrade already established linkages with domestic suppliers. As for the transfer of technology, it is pointed out that it usually happens through import of advanced technology from the mother company. Unfortunately, it remains within the circle of the MNE, given the abovementioned limited linkages with local companies. As recommendation to expand the technological transfer out of the circle, to local companies, the author argues for collaboration between universities and industries, as well as establishment of high-tech zones for enhancing horizontal and vertical channels of collaboration between companies. Johnson Matthey is depicted as a positive example of potential spillover effects. Dzatin Takrar, the acting cEo of Johnson Matthey, states that the company has established cooperation with more than 40 domestic companies, mainly for construction services and supply of raw materials, equipment and other goods. Important for the transfer knowledge and skills is that Johnson Matthey regularly organizes trainings for the employees, mostly for basic quality standards, health and safety, as well as environmental issues. Education and training is not provided to local suppliers, although this company offers guidance on meeting the international standards of 
quality. Still, Jovanovikj (2016) concludes that backward linkages in North Macedonia are on relatively low level. As main reasons for that he emphasizes insufficient capacities of local companies with respect to EU requirements, as well as the current legal framework, which does not stimulate spillover effects in terms of drawing and disseminating new or missing skills.

Although focused more on the direct effects of the FDIs, Janchevska (2014) provides similar findings. Her empirical analysis shows that the growth of the North Macedonian economy is highly driven by the FDI inflows. In order to further enhance the benefits for the long term economic development of the country, she suggests improvement of the country's infrastructure, as well as encouraging links between foreign and domestic companies.

Petkovski and Damoska Sekulovska (2018) investigate the impact of the FDI inflows in the automotive sector to the job properties in the manufacturing sector. The main pillars of their analysis are the job skills and wage distribution in the manufacturing sector in North Macedonia. They find distinct increase of the medium and high skilled labour force in the structure, which leads to conclusion that unlike in most CEE countries, job polarization in North Macedonia has not occurred.

In an earlier study, Apostolov (2016) focuses on the core links between foreign direct investments and innovation in Southeast Europe, with special reference to North Macedonia. Anticipating the idea that FDIs are an essential pillar for moving the society towards developed market economy, he examines the possibility that increase of the stock of capital would inevitably lead to increased innovation. His primary concern is the model of 'industry - government - university relationships', which is considered as basic analytical framework that explains the 'innovation system' of an economy. Based on a firm-level survey data from the World Bank Microdata Library, the emphasis is on the differences between domestic and foreign companies, in relation to the FDI inflows. In general, findings suggest that positive tendencies in the sectors of innovation and technology cannot be neglected.

The above presented empirical results allowed assuming the following research hypotheses.

$\mathrm{H} 1 \mathrm{FDIS}$ in North Macedonia increase the level of competitiveness of their local associates (suppliers, contractors, etc.).

H2 FDIs in North Macedonia increase the productivity of their local associates (suppliers, contractors, etc.), through expansion 
of the production capacities and/or development of new products and services.

H3 FDIs in North Macedonia increase the level of technological development of their local associates (suppliers, contractors, etc.), through investments in new and modern equipment.

H4 FDIs in North Macedonia increase the quality of the workforce of their local associates (suppliers, contractors, etc.), through investments in trainings and education.

H5 FDIS in North Macedonia increase the creativity and innovation of their local associates (suppliers, contractors, etc.).

H6 FDIs in North Macedonia stimulate their local associates (suppliers, contractors, etc.) to search for new methods of production and organizational practices, as well as to create better conditions for their employees.

$\mathrm{H} 7$ FDIs in North Macedonia increase the awareness of their local associates (suppliers, contractors, etc.) about the importance of management and marketing for their business success and development.

H8 FDIs in North Macedonia encourage their local associates (suppliers, contractors, etc.) to build trust and stable (long-term) connections with their business partners, suppliers, customers (clients), etc.

\section{Research Methodology}

For the purposes of this paper, a specially designed survey was conducted in order to get answers of the previously elaborated questions and hypotheses. With respect to the data used, it is worth to emphasize the similarity to the approach of Jordaan (2017). Namely, the author uses data obtained from two surveys, one for the producer companies, and one for the local suppliers, intended to provide detailed information for the extent and intensity of the linkages between these two groups of companies. The former survey covers both, foreign and domestic producer companies, whereas the latter is conducted upon a random sample of local suppliers. Our survey covered totally 28 domestic companies, half of which work with the foreign companies operating in the free economic zones in North Macedonia, whereas the other half do not. The questionnaire was sent to randomly selected companies, taking care of the balance of the sample size. ${ }^{1}$ This survey accounts for the business field of the companies (field), then the time of their active participation on the market (age), number of employees (size), and their orientation (в2в, 
or в 2c). Regarding the companies' field of activity, the survey makes a distinction between production, trade and services, but also allows for mixture of more than one area. As for the age of the companies, the time interval is 5 years, categorizing companies from up to 5 years old, 5 to 10,11 to 20 , and over 20 years old, whereas for the size, the survey recognizes companies with less than 20 employees, 21 to 50, 51 to 100 , and more than 100 employees. As can be noticed, the standard classification in this regards (up to 50 employees for small companies, 50 to 150 for medium, and over 150 employees for large companies) is not used. In relation to the companies' orientation, the survey groups companies working solely with firms (в2в), consumers (в2С), and both, firms and customers.

The survey was conducted electronically, using Google forms web service. Regarding the structure of the sample, one can easily notice from the illustrations presented below that the sub-samples are quite homogenous. Namely, with respect to the working field of the companies, number of employees, years of active operation on the market and biggest clients, the sample of domestic companies that cooperates with FDIs in North Macedonia has similar structure with the sample of domestic companies that do not cooperates with FDIs. ${ }^{2}$ This homogeneity provides solid ground for relevant and unbiased statistical analysis, since the differences that might affect the results are isolated. In other words, the properties of the companies cannot significantly affect the differences in the responses.

The survey provides variety of several different industry areas to group the companies, with 29 percent in construction and reconstruction of production facilities, 14 percent in maintenance of the equipment, 21 percent in raw materials supply, 7 percent in security, transport and logistics, and the remaining 29 percent in other industries.

The first part of the questionnaire collects data for the structure of the sample (as elaborated previously), in order to group the obtained results by different properties of the included companies. Such distinction is necessary for comparative statistical analysis. The second part quantifies the spillover effects that have actually occurred. The surveyed entities provide answers about their actions undertaken for business development in the past 5 years. The idea is that companies which cooperate with FDIS would have significantly higher investments in this respect than companies which have not established any relationships with foreign companies operating in the free economic zones in North Macedonia, thus expressing the positive spillover effects. 
TABLE 1 Structure of the Sample

\begin{tabular}{llrr}
\hline Category & Item & Yes & No \\
\hline Company's Activity & Production & 3 & 7 \\
& Trade & 4 & 1 \\
& Services & 2 & 2 \\
& All & 5 & 4 \\
\hline Active on the market & Up to 5 years & 2 & 5 \\
& 5-10 years & 5 & 1 \\
& 11-20 years & 2 & 5 \\
& Over 20 years & 5 & 3 \\
\hline Number of employees & Up to 20 employees & 6 & 3 \\
& 21-50 employees & 4 & 5 \\
& 51-100 employees & 3 & 5 \\
& Over 100 employees & 1 & 1 \\
\hline Biggest clients & Firms & 3 & 5 \\
& Consumers & 0 & 1 \\
& Firms and consumers & 11 & 8 \\
\hline
\end{tabular}

The last two parts focus on the perception of the owners/managers of the local companies of the potential spillover effects of the cooperation with FDIS, as well as the perception of the real impact of those spillovers. Therefore, in the third part local companies are asked to rank the determinants of their business' success, in order to see if there are any statistically significant differences in the mindset between the two groups. Additionally, in the fourth part companies evaluate their current position in the market, by several points, such as level of competitiveness, business relationships, quality of the capital and the workforce, etc. Answers provided here allow us to compare whether there are any differences in the perceptions between the two groups of local companies about their stance, or not. Positive spillovers would mean that companies which cooperate with FDIs would have higher self-awareness about their qualities and higher self-esteem.

With respect to the hypotheses established above, each question from 97 to 933 of the questionnaire (total of 27 questions) is linked to one of these hypotheses, allowing thus application of statistical methods for their testing. Given that more than one question is linked to each hypothesis, it is important to underline that they are representing different aspects. For example, one question represents the actual situation, whereas another is a reflection of the perceptions of the local companies for the same situation. The sta- 
tistical analysis is based on the equality tests regarding the sample mean $^{3}$ and median 4 of the two sub-sets of data (domestic companies that cooperate with FDIs operating in the free economic zones in North Macedonia and domestic companies that do not cooperate with these FDIS). These equality tests should provide answers to the hypotheses, by testing the statistical significance of the differences in the responses between the two data sub-sets.

The null hypothesis for all statistical tests used in the analysis (parametric and non-parametric) is that there are no differences between the provided answers, or there are no statistically significant differences between the means or the medians of the two data subsets. Thus, rejection of the null hypothesis would mean that cooperation with the FDIS in North Macedonia can be significant reason for certain differences between the domestic companies, with respect to their competitiveness and production. Why do we employ several different equality tests? The reason is simple, to provide more evidence for rejection of the null hypothesis, having in mind the assumptions and limitations of each of the tests used in the analysis. For example, parametric tests are known for the assumption of normal distribution of the data, or the bell-shaped distribution of the data around the mean. If this assumption is violated the results can be misleading. On the other hand, non-parametric tests are known as distribution-free tests, since they do not rely on the assumption of normal distribution of the data. Therefore, they are more suitable when this assumption is violated.

As two very important measures of central tendency, the mean and the median in normally distributed data are very close to each other, whereas if the data is not normally distributed the measurements can be significantly different. Thus, parametric test in fact test for differences in the sample means, whereas non-parametric tests are focused on the sample medians (Garth 2008). For simplicity reasons, in order not to widen the topic of this paper, further and deeper elaboration on the statistical techniques used in the analysis will not be provided.

Given the above, one cannot neglect the unique methodological approach of this paper. By using firm-level survey data, this research is not only taking into account the spillover effects from the foreign companies operating in the free economic zones in North Macedonia, but also accounts for the perceptions of the domestic entrepreneurs and managers of local companies. Opposite to this methodological approach, contemporary empirical literature in this area is mostly based on regression analysis, primarily using econo- 
metric techniques for panel data modelling (Doytch and Epperson 2012; Elkomy, Ingham, and Read 2016).

\section{Empirical Findings}

Table 2 presents the results for the questions of the second part (yes or no questions). It provides overview of the differences between local companies cooperating with foreign companies (MNES) operating in the free economic zones in North Macedonia and the ones that do not cooperate, with respect to their development in the past 5 years, or more precisely, their investment decisions. Namely, local companies here provide answers regarding their resent investments for expansion of the production facilities, improvement and modernizing of the equipment, increasing the quality of the workforce, development of new products, services and organizational practices. The descriptive table has three sections, or provides descriptive statistics for the overall data set (28 companies), as well as separately for the two sub-samples, or the two groups of companies, by question.

As can be seen, responses provided by the companies that cooperate with FDIs (part Yes $=1$ ) and companies that do not (part No $=2$ ) are not significantly different. This means that both groups of companies demonstrate similar behaviour. For instance, all 28 interviewed companies regularly follow the world trends and modern practices in their area of work. Most of the companies (both groups) pay attention to the quality of the workforce, by organizing different kinds of trainings for their employees and investing in improvement of their skills and abilities. Also, equal number of local companies that do and do not cooperate with the FDIs, 11 (of each group), regularly invest in modernizing of the equipment, against 3 companies (also of each group) which answered with no on this question. On the other hand, this proportion is lower (more balanced) when it comes to capital investments for building new production facilities and purchasing new equipment, for both groups of companies.

Besides the measures of central tendency and dispersion, table 2 also contains indicators regarding the distribution of the obtained responses (Jarque-Bera statistics and its $p$-value, or probability). This indicator shows that on a significance level of 0.1 (90\% confidence), there are some normally distributed data series, and some not normally distributed. Probability less than 0.1 (marked red) means non-normally distributed data. Sample results are not normally distributed for all questions. On disaggregated level (by group of companies), for the companies that do cooperate with the FDIs in the free economic zones in North Macedonia the results for ques- 
TABLE 2 Descriptive Statistics, Q7-Q14

\begin{tabular}{|c|c|c|c|c|c|c|c|c|c|}
\hline & Item & q7 & q8 & 99 & q10 & q11 & q12 & q13 & q14 \\
\hline \multirow[t]{5}{*}{ Total } & Mean & 1.39 & 1.50 & 1.21 & 1.11 & 1.07 & 1.18 & 1.14 & 1.00 \\
\hline & Median & 1 & 1.5 & 1 & 1 & 1 & 1 & 1 & 1 \\
\hline & Std. Dev. & 0.50 & 0.51 & 0.42 & 0.31 & 0.26 & 0.39 & 0.36 & 0.00 \\
\hline & Jarque-Bera & 4.71 & 4.67 & 9.05 & 53.25 & 147.81 & 13.93 & 24.92 & - \\
\hline & Probability & 0.0949 & 0.0970 & 0.0108 & 0.0000 & 0.0000 & 0.0009 & 0.0000 & - \\
\hline \multirow[t]{5}{*}{ Yes $=1$} & Mean & 1.43 & 1.57 & 1.21 & 1.14 & 1.00 & 1.14 & 1.21 & 1.00 \\
\hline & Median & 1 & 2 & 1 & 1 & 1 & 1 & 1 & 1 \\
\hline & Std. Dev. & 0.51 & 0.51 & 0.43 & 0.36 & 0.00 & 0.36 & 0.43 & 0.00 \\
\hline & Jarque-Bera & 2.34 & 2.34 & 4.53 & 12.46 & - & 12.46 & 4.53 & - \\
\hline & Probability & 0.3108 & 0.3108 & 0.1040 & 0.0020 & - & 0.0020 & 0.1040 & - \\
\hline \multirow[t]{5}{*}{$\mathrm{No}=2$} & Mean & 1.36 & 1.43 & 1.21 & 1.07 & 1.14 & 1.21 & 1.07 & 1.00 \\
\hline & Median & 1 & 1 & 1 & 1 & 1 & 1 & 1 & 1 \\
\hline & Std. Dev. & 0.50 & 0.51 & 0.43 & 0.27 & 0.36 & 0.43 & 0.27 & 0.00 \\
\hline & Jarque-Bera & 2.41 & 2.34 & 4.53 & 73.91 & 12.46 & 4.53 & 73.91 & - \\
\hline & Probability & 0.3001 & 0.3108 & 0.1040 & 0.0000 & 0.0020 & 0.1040 & 0.0000 & - \\
\hline
\end{tabular}

NOTES Q7: Have you invested in expanding your production facilities over the past 5 years? Q8: Have you invested in the procurement of new equipment over the past 5 years? Q9: Are you regularly modernizing the work equipment? Q10: Have you invested in the development of new products/services or an increase in the assortment in the past 5 years? Q11: Have you invested in the past 5 years in improving the skills and abilities of your employees? Q12: Does your company regularly organize trainings for employees and managers? Q13: Have you changed/adjusted the way of organizing your work in the last 5 years in order to increase your competitiveness on the market? Q14: Do you regularly follow the world trends, modern practices and achievements in your area of work?

tions q7, q8, q9 and q13 are normally distributed, whereas for the companies that do not cooperate with the FDIs the results for questions q7, q8, q9 and q12 are normally distributed. This is especially important when it comes to selection of appropriate method for statistical analysis (parametric or non-parametric equality tests). As for the questions from q15 to q33, same statistical description is presented in tables 3,4 and 5. Here, with respect to the sample mean, most significant differences in the provided answers have questions q17, q18, q21 to q26 and q29, whereas most similar responses have questions q15, q19 and q30. With respect to the sample median, companies of the two groups have provided slightly different answers for questions q19, q21 to q26 and q29, whereas no differences between the sample medians have questions p28, $\mathrm{p}_{2} 2$ and $\mathrm{p} 33^{5}$

As shown by the mean values of the results which emphasizes the differences between the two groups, companies that do not cooper- 
TABLE 3 Descriptive Statistics of the Scaled Questions: Total

\begin{tabular}{lrrrrr}
\hline Question & Mean & Median & Std. Dev. & Jarque-Bera & Probability \\
\hline q15 & 3.75 & 4 & 1.08 & 1.96 & 0.3759 \\
q16 & 4.39 & 4 & 0.63 & 1.64 & 0.4410 \\
q17 & 4.04 & 4 & 0.84 & 2.72 & 0.2569 \\
q18 & 4.00 & 4 & 1.12 & 3.02 & 0.2214 \\
q19 & 4.29 & 5 & 0.98 & 5.48 & 0.0646 \\
q20 & 4.25 & 4 & 0.75 & 2.21 & 0.3318 \\
q21 & 4.11 & 5 & 1.20 & 6.00 & 0.0499 \\
q22 & 4.14 & 5 & 1.21 & 6.47 & 0.0394 \\
q23 & 4.21 & 5 & 1.07 & 6.53 & 0.0382 \\
q24 & 4.21 & 5 & 1.03 & 5.23 & 0.0730 \\
q25 & 4.36 & 5 & 0.87 & 5.66 & 0.0589 \\
q26 & 4.14 & 5 & 1.21 & 6.47 & 0.0394 \\
q27 & 4.32 & 5 & 0.90 & 4.56 & 0.1022 \\
q28 & 4.04 & 4 & 0.79 & 2.14 & 0.3438 \\
q29 & 4.25 & 4 & 0.70 & 1.54 & 0.4626 \\
q30 & 4.39 & 5 & 0.79 & 3.90 & 0.1421 \\
q31 & 4.43 & 5 & 0.74 & 3.92 & 0.1407 \\
q32 & 4.32 & 5 & 0.90 & 4.56 & 0.1022 \\
q33 & 4.75 & 5 & 0.52 & 27.12 & 0.0000 \\
\hline
\end{tabular}

ate with MNES operating in the free economic zones in North Macedonia have higher score only for the questions q11, q16, q19 and q20, meaning that these companies value more the significance of the long-term relationship with their business partners and regular customers for survival and development of their companies, as well as recognize better the role of the management. Additionally, according to the provided answers, these companies have made higher investments in the past 5 years for improvement of the skills and abilities of their employees, compared to the companies cooperating with the FDIS.

Both groups of companies on average have provided similar answers to the questions, q7, q9, q10, q12, q14, q15 and q30, whereas for the rest 16 questions, the differences in the responses go in favour of the companies cooperating with the FDIS.

Given that descriptive provide only general indications, a deeper statistical analysis is required to derive conclusions. Summary of the results of the equality tests is provided in table 6 . It contains the test statistic and its corresponding $p$-value (probability), which shows the lowest significance level for rejection of the null hypothesis. ${ }^{6}$ In 


\section{Snezhana Hristova and Dusica Stevcevska-Srbinoska}

TABLE 4 Descriptive Statistics of the Scaled Questions: Yes $=1$

\begin{tabular}{llrrrr}
\hline Question & Mean & Median & Std. Dev. & Jarque-Bera & Probability \\
\hline q15 & 3.71 & 3.5 & 1.14 & 1.17 & 0.5566 \\
q16 & 4.29 & 4 & 0.73 & 0.96 & 0.6187 \\
q17 & 4.29 & 4.5 & 0.83 & 1.57 & 0.4557 \\
q18 & 4.71 & 4 & 0.92 & 1.74 & 0.4188 \\
q19 & 4.21 & 4 & 0.80 & 1.24 & 0.5384 \\
q20 & 4.14 & 4 & 0.77 & 0.91 & 0.6330 \\
q21 & 4.57 & 5 & 0.65 & 3.17 & 0.2050 \\
q22 & 4.64 & 5 & 0.63 & 5.96 & 0.0508 \\
q23 & 4.50 & 5 & 0.85 & 1.45 & 0.0007 \\
q24 & 4.57 & 5 & 0.65 & 3.17 & 0.2050 \\
q25 & 4.64 & 5 & 0.63 & 5.96 & 0.0508 \\
q26 & 4.64 & 5 & 0.63 & 5.96 & 0.0508 \\
q27 & 4.50 & 5 & 0.76 & 2.84 & 0.2420 \\
q28 & 4.21 & 4 & 0.80 & 1.24 & 0.5384 \\
q29 & 4.50 & 5 & 0.65 & 1.81 & 0.4039 \\
q30 & 4.43 & 5 & 0.85 & 2.48 & 0.2899 \\
q31 & 4.57 & 5 & 0.65 & 3.17 & 0.2050 \\
q32 & 4.43 & 5 & 0.76 & 1.96 & 0.3751 \\
q33 & 4.86 & 5 & 0.36 & 1.25 & 0.0020 \\
\hline
\end{tabular}

TABLE 5 Descriptive Statistics of the Scaled Questions: No $=2$

\begin{tabular}{lrrrrr}
\hline Question & Mean & Median & Std. Dev. & Jarque-Bera & Probability \\
\hline q15 & 3.79 & 4 & 1.05 & 0.88 & 0.6452 \\
q16 & 4.5 & 4.5 & 0.52 & 2.33 & 0.3114 \\
q17 & 3.79 & 4 & 0.80 & 0.24 & 0.5384 \\
q18 & 3.93 & 4.5 & 1.33 & 1.92 & 0.3824 \\
q19 & 4.36 & 5 & 1.15 & 4.37 & 0.1124 \\
q20 & 4.36 & 4.5 & 0.74 & 1.39 & 0.4991 \\
q21 & 3.64 & 4 & 1.45 & 1.42 & 0.4905 \\
q22 & 3.64 & 4 & 1.45 & 1.42 & 0.4905 \\
q23 & 3.93 & 4 & 1.21 & 1.71 & 0.4261 \\
q24 & 3.86 & 4 & 1.23 & 1.56 & 0.4581 \\
q25 & 4.07 & 4 & 1.00 & 1.24 & 0.5367 \\
q26 & 3.64 & 4 & 1.45 & 1.42 & 0.4905 \\
q27 & 4.14 & 4.5 & 1.03 & 1.59 & 0.4516 \\
q28 & 3.86 & 4 & 0.77 & 0.91 & 0.6330 \\
q29 & 4.00 & 4 & 0.68 & 0.26 & 0.8784 \\
q30 & 4.36 & 4.5 & 0.74 & 1.39 & 0.4991 \\
\hline & & & & Continued on the next page
\end{tabular}


Continued on the next page

\begin{tabular}{llllll}
\hline q31 & 4.29 & 4.5 & 0.83 & 1.57 & 0.4557 \\
q32 & 4.21 & 5 & 1.05 & 1.99 & 0.3701 \\
q33 & 4.64 & 5 & 0.63 & 5.96 & 0.0508 \\
\hline
\end{tabular}

NOTES q15: The role of marketing is crucial for the survival and development of our business; q16: The development and maintenance of stable and long-term relationships with our associates and suppliers is crucial for the survival and development of our business; q17: The quality of our products/services depends on the quality and motivation of our employees; q18: The survival and progress of our business depends on the satisfaction of the employees in relation to the amount of their salary, working conditions, the opportunity for advancement and improvement, the working atmosphere, etc.; q19: Regular consumers are of particular importance for the survival of our business; q20: The responsibility for the success of our company's operations lies entirely with the management; q21: Cooperation with a foreign company operating in North Macedonia contributes (will contribute) to the increase of the competitiveness of our company; q22: The cooperation with a foreign company operating in North Macedonia contributes (would contribute) to the increase of the productivity of our company; q23: Cooperation with a foreign company operating in North Macedonia contributes (will contribute) to the increase the innovation of our company; q24: The cooperation with a foreign company operating in North Macedonia contributes (will contribute) to the improvement of the working processes of our company; q25: The cooperation with a foreign company operating in North Macedonia contributes (would contribute) to the promotion of the cooperation with our business partners; q26: The cooperation with a foreign company operating in North Macedonia contributes (would contribute) to the improvement of the working conditions of our employees; q27: The cooperation with a foreign company operating in North Macedonia leads (will lead) to transfer of technology and knowledge; q28: The degree of competitiveness of your company on the market; q29: The success of your company's management; q30: The quality of the equipment at your disposal; q31: The quality and capability of your employees; q32: The innovation of your company; q33: Collaboration with your business partners, suppliers and consumers.

total, four statistical tests are applied: $t$-test, ANovA, Chi-square and Kruskal-Wallis.

Within the groups of tests, one can see that both parametric tests ( $t$-test and ANOvA) provide the same results. On the other hand, the Kruskal-Wallis test is slightly stricter than the Chi-square test, in terms of rejection of the null hypothesis.

In this regards, table 6 shows that most of the differences are not statistically significant at the 0.1 significance level, therefore, not providing sufficient evidence for rejection of the null hypothesis. However, the null hypothesis can be rejected when it comes to questions q21, q22, q24, q25, q26 and q29, for the differences in the sample mean, and questions q22, q26 and q29 for differences in the sample median.

In the context of the distribution of the data, since the data se- 
TABLE 6 Statistical Tests: Results

\begin{tabular}{|c|c|c|c|c|c|c|c|c|}
\hline \multirow[t]{3}{*}{ Question } & \multicolumn{4}{|c|}{ Mean equality tests } & \multicolumn{4}{|c|}{ Median equality tests } \\
\hline & \multicolumn{2}{|c|}{$t$-test } & \multicolumn{2}{|c|}{ Anova $F$-test } & \multicolumn{2}{|c|}{ Med. $\chi^{2}$} & \multicolumn{2}{|c|}{ Kruskal-Wallis } \\
\hline & Value & Prob. & Value & Prob. & Value & Prob. & Value & Prob. \\
\hline q7 & 0.37 & 0.7115 & 0.14 & 0.7115 & 0.15 & 0.6988 & 0.10 & 0.7477 \\
\hline q8 & 0.74 & 0.4683 & 0.54 & 0.4683 & 0.57 & 0.4497 & 0.41 & 0.5201 \\
\hline q9 & 0.00 & 1.0000 & 0.00 & 1.0000 & 0.00 & 1.0000 & 0.00 & 1.0000 \\
\hline q10 & 0.59 & 0.5585 & 0.35 & 0.5585 & 0.37 & 0.5412 & 0.10 & 0.7477 \\
\hline q11 & -1.47 & 0.1530 & 2.17 & 0.1530 & 2.15 & 0.1422 & 0.41 & 0.5201 \\
\hline $\mathrm{q} 12$ & -0.48 & 0.6369 & 0.23 & 0.6369 & 0.24 & 0.6217 & 0.10 & 0.7477 \\
\hline q13 & 1.06 & 0.2975 & 1.13 & 0.2975 & 1.17 & 0.2801 & 0.41 & 0.5201 \\
\hline q14 & 0.00 & 1.0000 & 0.00 & 1.0000 & 0.00 & 1.0000 & 0.00 & 1.0000 \\
\hline q15 & -0.17 & 0.8644 & 0.03 & 0.8644 & 0.16 & 0.6857 & 0.03 & 0.8722 \\
\hline q16 & -0.90 & 0.3773 & 0.81 & 0.3773 & 0.14 & 0.7047 & 0.41 & 0.5201 \\
\hline q17 & 1.63 & 0.1161 & 2.64 & 0.1161 & 2.49 & 0.1147 & 2.23 & 0.1354 \\
\hline q18 & 0.33 & 0.7431 & 0.11 & 0.7431 & 0.14 & 0.7047 & 0.00 & 0.9817 \\
\hline q19 & -0.38 & 0.7062 & 0.15 & 0.7062 & 0.00 & 1.0000 & 0.76 & 0.3827 \\
\hline q20 & -0.75 & 0.4611 & 0.56 & 0.4611 & 0.58 & 0.4450 & 0.51 & 0.4763 \\
\hline q21 & 2.19 & 0.0375 & 4.81 & 0.0375 & 0.00 & 1.0000 & 2.44 & 0.1182 \\
\hline q22 & 2.37 & 0.0255 & 5.61 & 0.0255 & 0.00 & 1.0000 & 3.05 & 0.0808 \\
\hline q23 & 1.45 & 0.1602 & 2.09 & 0.1602 & 0.00 & 1.0000 & 1.48 & 0.2234 \\
\hline q24 & 1.92 & 0.0657 & 3.69 & 0.0657 & 0.00 & 1.0000 & 2.03 & 0.1543 \\
\hline q25 & 1.81 & 0.0819 & 3.28 & 0.0819 & 0.00 & 1.0000 & 2.23 & 0.1354 \\
\hline q26 & 2.37 & 0.0255 & 5.61 & 0.0255 & 0.00 & 1.0000 & 3.05 & 0.0808 \\
\hline q27 & 1.05 & 0.3052 & 1.09 & 0.3052 & 0.00 & 1.0000 & 0.68 & 0.4082 \\
\hline q28 & 1.20 & 0.2403 & 1.44 & 0.2403 & 1.47 & 0.2248 & 1.27 & 0.2603 \\
\hline q29 & 1.99 & 0.0573 & 3.96 & 0.0573 & $3 \cdot 74$ & 0.0530 & 3.13 & 0.0769 \\
\hline q30 & 0.24 & 0.8151 & 0.06 & 0.8151 & 0.00 & 1.0000 & 0.15 & 0.6961 \\
\hline q31 & 1.02 & 0.3172 & 1.04 & 0.3172 & 0.00 & 1.0000 & 0.68 & 0.4082 \\
\hline q32 & 0.62 & 0.5411 & 0.38 & 0.5411 & 0.00 & 1.0000 & 0.10 & 0.7477 \\
\hline q33 & 1.10 & 0.2822 & 1.21 & 0.2822 & 0.00 & 1.0000 & 0.48 & 0.4907 \\
\hline
\end{tabular}

ries for questions q21, q22, q24, q25 and q26 are not normally distributed, parametric tests are not valid, which is further emphasized by the small sample size. In this case results from non-parametric tests should be considered as relevant. As for question q29, since the data are normally distributed, parametric tests provide reliable results, even though all four tests here reject the null hypothesis at a 0.1 significance level.

Following the statistical analysis, hypotheses 1, 3, 4, 5 and 8 are rejected, whereas hypotheses 2,6 and 7 are partly rejected. The null 
hypothesis is also rejected. ${ }^{7}$ A partly rejected hypothesis means that, out of the several related questions, only some (one) are rejected, not all. For example, the second hypothesis, related to the productivity spillovers, out of 3 relevant questions attached to this hypothesis (q7, q10 and q22), there are statistically proven differences in the responses only for question q22. The results of this question, statistically significant differences, go in favour of the established hypothesis, whereas the results for the other two questions reject it. Hence, hypothesis 2 is partly rejected. It is same with hypotheses 6 and 7 .

Referring to questions q22, q26 and q29, for which there are statistically significant differences in the provided responses, it means that companies cooperating with some of the MNES operating in the free economic zones in North Macedonia on average have higher beliefs that cooperation with foreign companies would lead to productivity increase of the local company (question q22) and improvement of the working conditions for the employees (question 26). Also, these groups of companies on average evaluate more the success of their management (question q29). As for the other questions, both groups of companies included in the survey provided similar answers, or answers that do not differ significantly.

\section{Conclusions}

The aim of the paper was to examine theoretically and empirically the spillover effects of FDIs (multi-national enterprises) in the Republic of North Macedonia operating in the free economic zones. In particular, given the nature of the MNE's in North Macedonia, as well as their market orientation, the analysis focuses on the backward vertical spillover effects. In other words, those are the linkages between the foreign companies and their local suppliers, partners, associates, etc. Besides benefits provided by the North Macedonian Government, other main factors influencing the decision to move, or expand, their production in North Macedonia are: cheaper labour force, favourable geographical location, connection and proximity to European markets, favourable business environment, low administrative barriers, good transport and communal infrastructure, etc.

Spillover effects, in terms of productivity and competitiveness increase, are observed through three main channels: transfer of technology; transfer of knowledge; and creativity and innovation. The results suggest that in general North Macedonian companies do believe that cooperation with FDIs would lead to higher transfer of knowledge and technology, although there is not enough empirical evidence supporting this claim. There is also no empirical support 
for the assumption that cooperation with FDIs has significant influence on the investment decisions of the local companies, as well as that FDIS in North Macedonia stimulate the search of new and innovative methods of production and organizational practices. Local companies that cooperate with FDIs recognize the contribution of their management for the success of the company and the importance of the working satisfaction of their employees, but they do not provide any additional training for professional improvement. FDIS in North Macedonia encourage building of trust and stable connections of the local companies with their suppliers and customers, but do not increase the awareness of the local companies about the importance of the marketing for their business development.

However, one should also have in mind that the limitations and assumptions that burden this research. Possible limitations in this regard can be viewed from two different aspects, technical and substantial. From technical point of view, limitations can be linked to the sample selection process, the size of the sample and the justification of the applied statistical methods. Namely, relatively small sample size (only 28 companies included in the survey), selected in methodologically questionable manner, can result in biased and misleading results. Furthermore, equality tests used to analyze the results obtained from the survey do not provide important information, such as causal relationship, dynamics, extent and intensity of the spillover effects. Practically, the whole analysis is intended only to determine if there are spillover effects, in terms of increased productivity and competitiveness, from the foreign companies in the free economic zones in North Macedonia, to their local partners/associates/suppliers. In other words, the intention is to provide evidence of the existence of backward vertical spillover effects in North Macedonia, aimed to test the justification of the government's determination to attract foreign investments. Having in mind the purpose of the research, the assumptions that the aforementioned limitations do not significantly affect the obtained results and provided conclusions are justified.

An additional argument that can be treated as limitation is that this study, and consequently its findings, is based on perceptions, and not on robust statistical data, which brings out the conceptual weaknesses related to perceptions in first place. However, given that such approach widens the perspectives in the analysis of the spillover effects of FDIS, and provides opportunity for further research and discussion, this limitation might be the most important added value of this paper. 


\section{Notes}

1 Given the limitations that might arise when using uneven samples in the statistical analysis, this research is based on even number of companies cooperating and not cooperating with foreign companies operating in North Macedonia

2 In the following illustrations, as well as further in the tables, companies that cooperate with FDIs in North Macedonia are given value 1 (yes), whereas companies that do not have value 2 (no).

$3 t$-test and ANova (parametric tests).

4 Chi-square test and Kruskal-Wallis test (non-parametric tests).

5 Differences between the central tendency indicators (mean and median) between the two groups of companies.

6 Null hypothesis of all tests applied is that there are no statistically significant differences in the provided answers.

7 This is only of informative nature and not taken into account when deriving the conclusion.

\section{References}

Apostolov, M. 2016. ‘Foreign Direct Investments Induced Innovation? A Case Study - North Macedonia.' Comparative Economic Research 19 (1): $5^{-25}$.

Blomström, M., and A. Kokko. 2001. 'FDI, Human Capital and Education in Developing Countries.' Paper presented at the technical meeting organized by the ofcD Development Centre, Paris, 13-14 December.

Bruhn, N. C. P., and L. L. C. Calegario. 2014. 'Productivity Spillovers from Foreign Direct Investment in the Brazilian Processing Industry.' Brazilian Administration Review 11 (1): 22-46.

Buckley, P., J. Clegg, A. Cross, and H. Tan. 2005. 'China's Inward Foreign Direct Investment Success: Southeast Asia in the Shadow of the Dragon.' Multinational Business Review 13 (1): 3-31.

Carkovic, M. V., and R. Levine. 2002. 'Does Foreign Direct Investment Accelerate Economic Growth?' Department of Finance Working Paper, University of Minnesota, Minneapolis, MN.

Cuyvers, L., J. Plasmans, R. Soeng, and D. Van den Bulcke. 2008. ‘Determinants of Foreign Direct Investment in Cambodia: CountrySpecific Factor Differentials.' cas Discussion Paper 61, University of Antwerp, Antwerp.

Doytch, N., and N. Epperson. 2012. 'FDI and Entrepreneurship in Developing Countries.' Global Science and Technology Forum Business Review 1:120-125.

Elkomy, S., H. Ingham, and R. Read. 2016. 'Economic and Political Determinants of the Effects of FDI on Growth in Transition and Developing Countries.' Thunderbird International Business Review 58 (4): 347-62. 
Garth, A. 2008. 'Analysing Data Using spss.' https://students.shu.ac.uk/ lits/it/documents/pdf/analysing_data_using_spss.pdf.

Gerschewski, S. 2013. 'Do Local Firms Benefit from Foreign Direct Investment? An Analysis of Spillover Effects in Developing Countries.' Asian Social Science 9 (4): 67-76.

Gorodnichenko, Y., J. Svejnar, and K. Terrell. 2007. 'When Does FDI Have Positive Spillovers? Evidence from 17 Emerging Market Economies.' IzA Discussion Paper 3079, Institute of Labor Economics, Bonn.

Janchevska, M. 2014. 'The Importance of FDI in the North Macedonian Economy.' Master Thesis, University of Ljubljana.

Javorcik, B. S., and M. Spatareanu. 2005. 'Disentangling FDI Spillover Effects: What Do Firm Perceptions Tell Us?' In Does Foreign Direct Investment Promote Development? Edited by T. H. Moran, E. M. Graham, and M. Blomström, 45-71. Washington, DC: Institute for International Economics.

Jordaan, J. A. 2017. 'Producer Firms, Technology Diffusion and Spillovers to Local Suppliers.' Environment and Planning 49 (12): 271838.

Jovanovikj, A. 2016. 'The Effects of Foreign Direct Investments on Employment in North Macedonia.' Master Thesis, University of Ljubljana.

Jude, C. 2012. 'Horizontal and Vertical Technology Spillovers from FDI in Eastern Europe.' LEo Working Papers 710, University of Orleans, Orleans.

Karahan, O. 2016. 'Technology Spillover from Foreign Direct Investment in Turkey.' International Journal of Business and Economic Sciences Applied Research 9 (3): 7-12.

Kokko, A. 1992. 'Foreign Direct Investment, Host Country Characteristics, and Spillovers.' PhD Dissertation, Stockholm School of Economics, Stockholm.

Krammer, S. M. S. 2010. 'International R\&D Spillovers in Emerging Markets: The Impact of Trade and Foreign Direct Investment.' The Journal of International Trade \& Economic Development 19 (4): 591-623.

Lalitchandra, B. N. 2015. 'Towards the Need of Efficiency: Seeking FDI for a Faster and More Inclusive Growth in India.' CLEAR International Journal of Research in Commerce \& Management 6 (5): 35-38.

Marin, A., and M. Bell. 2006. 'Technology Spillovers from Foreign Direct Investment (FDI): the Active Role of MNC Subsidiaries in Argentina in the 1990s.' Journal of Development Studies 42 (4): 678-97.

Narula, R., and B. Portelli. 2004. 'Foreign Direct Investment and Economic Development: Opportunities and Limitations from a Developing Country Perspective.' Infonomics Research Memorandum Series 9, Maastricht Economic Research Institute on Innovation and Technology, Maastricht. 
Navaretti, G. B., T. Venables, and F. Barry. 2004. 'Multinational Firms in the World Economy.' Transnational Corporations 14 (3): 141-64.

Nicolini, M., and L. Resmini. 2010. 'FDi Spillovers in New EU Member States: Which Firms Create Them and Which Firms Really Benefit?' Economics of Transition Volume 18 (3): 487-511.

Parnell, J. A. 2014. Strategic Management: Theory and Practice. 4th ed. Los Angeles: Sage.

Petkovski, V., and J. Damoska Sekulovska. 2018. 'The Influence of FDIs Inflow in the Automotive Sector on the Job Content: Properties in the North Macedonian Economy Manufacturing Sector.' Annual of the Faculty of Economics - Skopje, 351-64.

Romer, D. 1993. 'Openness and Inflation: Theory and Evidence.' The Quarterly Journal of Economics 108 (4): 869-903.

Saggi, K. 2002. 'Trade, Foreign Direct Investment, and International Technology Transfer: A Survey.' The World Bank Research Observer 17 (2): 191-235.

Stancik, J. 2007. 'Horizontal and Vertical FDi Spillovers: Recent Evidence from the Czech Republic.' CERGE-EI Working Paper Series 340, Center for Economic Research and Graduate Education, Prague.

Vahter, P., and J. Masso. 2005. 'Home versus Host Country Effects of FDI: Searching for New Evidence of Productivity Spillovers.' Working Papers of Eesti Pank 13, Bank of Estonia, Tallinn. 